\title{
Dietary Xylo-oligosaccharide stimulates intestinal bifidobacteria and lactobacilli but has limited effect on intestinal integrity in rats
}

\author{
Ellen Gerd Christensen ${ }^{1}$, Tine Rask Licht ${ }^{1}$, Thomas Dyrmann Leser $^{2}$ and Martin lain Bahl ${ }^{1 *}$
}

\begin{abstract}
Background: Consumption of prebiotics may modulate gut microbiota, subsequently affecting the bacterial composition, metabolite profile, and human health. Previous studies indicate that also changes in intestinal integrity may occur. In order to explore this further we have investigated the effect of the putative prebiotic xylo-oligosaccharides (XOS) on the gut microbiota and intestinal integrity in male Wistar rats. As changes in intestinal integrity may be related to the expected bifidogenic effect of XOS, we additionally addressed effects of supplementation with a commensal Bifidobacterium pseudolongum (BIF) isolated from the same breed of laboratory rats.
\end{abstract}

Results: Changes in faecal and caecal bacterial composition determined by $16 \mathrm{~S}$ rRNA gene sequencing and quantitative PCR for selected bacterial groups revealed that the overall bacterial composition did not differ markedly between the control (CON), XOS, and BIF groups, when correcting for multiple comparisons. However as hypothesised, the relative abundance of Bifidobacterium spp. was increased in XOS-fed rats as compared to CON in faecal samples after the intervention. Also Lactobacillus spp. was increased in both the XOS and BIF groups in caecum content compared to CON. Intestinal permeability determined in vivo by FITC-dextran permeability and in vitro using extracted caecum water in trans-epithelial resistance (TER) assay showed no effect on intestinal integrity in either the XOS or the BIF groups. However, the expression of occludin, which is part of the tight junction complex, was increased in the XOS group compared to the CON group.

Conclusions: Supplementation with XOS or a commensal Bifidobacterium pseudolongum had very limited effects on intestinal integrity in rats as only significant change in expression of a single tight junction protein gene was found for the XOS group.

Keywords: Xylooligosaccharides, Bifidobacterium, Gut microbiota, Intestinal integrity

\section{Background}

The complex microbial community of the gut environment is thought to interact with the host organism and to affect human health [1]. Modulation of the gut microbial composition by consumption of specific substances such as prebiotics and probiotics may therefore affect intestinal and systemic health. Previous studies of the modulatory effect of established prebiotics as well as putative prebiotics have mainly focused on Bifidobacterium spp. and Lactobacillus spp. in the microbiota [2-5] as

\footnotetext{
* Correspondence: mbah@food.dtu.dk

${ }^{1}$ Division of Food Microbiology, National Food Institute, Technical University of Denmark, Mørkhøj Bygade 19, Søborg DK-2860, Denmark

Full list of author information is available at the end of the article
}

these are claimed to have beneficial effects on health [6]. Effects on other bacterial groups, potentially with adverse effects on health, may thus have been overlooked. The development of high-throughput sequencing techniques now makes it feasible to survey the entire microbiota. In addition to determining the effect of pre- and probiotics on the complete gut microbiota, it is important to understand how such effects influence host health. An important marker for health is intestinal integrity, as increased intestinal gut permeability previously has been connected to intestinal disorders including inflammatory bowel diseases and coeliac disease [7,8]. Gut wall permeability can be determined in vivo by examining the permeability of molecules with a defined size, such as FITC-dextran 
[9] and CrEDTA [10]. In addition, effects on intestinal integrity can be estimated by determining the expression and localization of tight-junction proteins. Effects of gut content on intestinal integrity may also be assessed in vitro by examining the effect of metabolites from the community found in e.g. faecal water on trans-epithelial resistance (TER) in epithelial cell monolayers [11,12].

Several previous studies have examined the effect of prebiotic supplementation on pathogen invasion in animal challenge studies. Prebiotic fructo-oligosaccharides (FOS) and the putative prebiotic xylo-oligosaccharides (XOS) [13] have previously been found to stimulate translocation of Salmonella in rats [14,15] and mice [16]. Here the prebiotics also stimulated increase in Bifidobacterium spp. [14,17] and Lactobacillus spp. [14,15], which are both considered to have a beneficial effect on host health. In connection to this, FOS has been found to increase permeability of CrEDTA in rats, while also stimulating these two groups of bacteria [18]. Also, we have recently shown a trend for an inverse association between the relative abundance of Bifidobacterium spp. in human faeces and the effect of faecal water on trans-epithelial resistance (TER) [11]. This however does not necessarily implicate that bifidobacteria or lactobacilli are involved in the observed adverse effects, but the effects could be attributed to other factors, such as changes in non-investigated bacterial groups. The modulation of the microbiota as whole by prebiotics may thus result in adverse effects on the intestinal integrity, which could be due to changes in metabolic outputs of the community. Also in vitro studies show that $B$. infantis produce compounds that increase TER [19] and that UV-killed B. bifidum and B. breve increase TER [20]. Furthermore in vivo studies show that bifidobacteria increase intestinal integrity in animal disease models $[21,22]$. We hypothesize, that an increase in Bifidobacterium spp. caused by e.g. consumption of prebiotics may affect the intestinal integrity indirectly by affecting proliferation and/or metabolic activity of other bacteria, causing conditions that allow increase in Salmonella translocation upon challenge. The aim of the present study is thus to determine effects of XOS and commensal bifidobacteria on the gut microbiota and the intestinal integrity in healthy, unchallenged rats using high throughput $16 \mathrm{~S}$ rRNA gene sequencing quantitative PCR and three different methods to determine intestinal permeability. The study provides new insights into understanding interactions between gut bacterial community composition and intestinal integrity.

\section{Methods}

Isolation of a commensal Bifidobacterium spp. from rats

Faecal samples from Wistar rats were obtained prior to the animal studies from the same facility (Taconic, Lille Skensved, Denmark). Bifidobacteria were isolated from the faecal samples by plating on Bifidus Selective Medium (BSM) agar (Fluka), incubation anaerobically at $37^{\circ} \mathrm{C}$ for three days, selection for correct colony morphology (pink or dark brown colonies) and verification by PCR using bifidobacteria-specific primers BifF/BifR (Table 1). Universal primers $27 \mathrm{~F}$ (5'AGA GTT TGA TYM TGG CTC AG-3') and 907R (5'- CCG TCA ATT CMT TTG AGT TT-3') were used for sequencing. The PCR products obtained with the universal primers were purified by gel-electrophoresis and the $16 \mathrm{~S}$ rRNA gene partially sequenced using the same primers. Four isolates were found to be identical and have $99.4 \%$ sequence homology over 726 bp to Bifidobacterium pseudolongum subsp. globosum strain JCM 5820 by BLAST search [23]. Since the four isolated strains were identical, we chose a single strain, designated B. pseudolongum TR2_39 for this study. Aliquots of TR2_39 (1 ml) were frozen in glycerol and stored at $-80^{\circ} \mathrm{C}$.

\section{Animals and housing}

6 week-old male Wistar rats were purchased from Taconic (Lille Skensved, Denmark) and originated from the same stable where faecal samples used to isolate TR2_39 were collected. On arrival the animals were housed in pairs and had ad libitum access to chow (Altromin 1324) and drinking water throughout the experiment. The environment was controlled with 12-hour light/dark cycles, temperature at $22 \pm 1^{\circ} \mathrm{C}$, relative humidity at $55 \pm 5 \%$ and $8-10$ air changes per hour. Animals were observed twice a day. Animal experiments were carried out at the National Food Institute, Technical University of Denmark (Mørkhøj facilities). Ethical approval was given by the Danish Animal Experiments Inspectorate (authorization number 2012-15-2934-00089). The experiments were overseen by the National Food Institutes in-house Animal Welfare Committee.

Four days after arrival the animals were weighed and cages were allocated randomly to the three experimental groups, namely CON (dosed with sterile water), XOS (dosed with XOS), and BIF (dosed with B. pseudolongum TR2_39) with 16 animals (8 cages) in each group. The XOS was obtained from Shandong Longlive BioTechnology CO. Ltd, China as 95\% pure powder extracted from corncob (zea). To limit potential effects of co-housing and coprophagia on the gut microbial composition, the animals were housed together for additionally 2 weeks before the dosing period was initiated. During the acclimatization period the weight of the animals, and the water and feed intake was monitored as intake per cage per day.

During the intervention period the animals were given oral gavage with $1 \mathrm{ml}$ milliQ water (CON), $2 \mathrm{ml} 500 \mathrm{mg} / \mathrm{ml}$ XOS (XOS) or $1 \mathrm{ml}$ B. pseudolungum TR2_39, approximately $2.2-6.2 * 10^{8} \mathrm{CFU} / \mathrm{ml}$ (BIF) every second day for 
Table 1 Primers used for PCR and quantitative PCR

\begin{tabular}{|c|c|c|c|c|}
\hline Target & Primer & Primer sequence $\left(5^{\prime}-3^{\prime}\right)$ & Size (bp) & Ref \\
\hline \multirow[t]{2}{*}{ Bifidobacterium spp. } & BifF & GCGTGCTTAACACATGCAAGTC & 126 & [24] \\
\hline & BifR & CACCCGTTTCCAGGAGCTATT & & \\
\hline \multirow[t]{2}{*}{ Lactobacillus spp. } & LactoAll_1F & AGCAGTAGGGAATCTTCCA & 341 & {$[25,26]$} \\
\hline & LactoAll_1R & CACCGCTACACATGGAG & & \\
\hline \multirow[t]{2}{*}{ Akkermansia muciniphila } & AM1 & CAGCACGTGAAGGTGGGGAC & 327 & {$[27]$} \\
\hline & $\mathrm{AM} 2$ & CCTTGCGGTTGGCTTCAGAT & & \\
\hline \multirow[t]{2}{*}{ Universal bacteria } & HDA1 & ACTCCTACGGGAGGCAGCAGT & 200 & {$[28]$} \\
\hline & HDA2 & GTATTACCGCGGCTGCTGGCAC & & \\
\hline \multirow[t]{2}{*}{ Beta-actin (Actb) } & ACTB_A & CACCCGCGA GTACAACCTT & 207 & [29] \\
\hline & ACTB_B & CCCATACCCACCATCACACC & & \\
\hline \multirow[t]{2}{*}{ Glyceraldehyd-3-phosphate (Gapdh) } & GAPDH2_A & CAAGTTCAACGGCACAGTCAAG & 123 & [30] \\
\hline & GAPDH2_B & ACATACTCAGCACCAGCATCAC & & \\
\hline \multirow[t]{2}{*}{ Mucin 2 (Muc2) } & MUC2_A & TCCCTCTTACAAGGGCAATG & 123 & [31] \\
\hline & MUC2_B & TTCCAGCTGTTCCCAAAGTC & & \\
\hline \multirow[t]{2}{*}{ Claudin-1 } & CLDN-1_A & TGTCCACCATTGGCATGAAG & 118 & [32] \\
\hline & CLDN-1_B & GCCACTAATGTCGCCAGACC & & \\
\hline \multirow[t]{2}{*}{ Occludin } & OCLN_A & GCCTITTGCTTCATCGCTTC & 125 & [30] \\
\hline & OCLN_B & AACACCATGATGCCCAGGAT & & \\
\hline \multirow[t]{2}{*}{ Zonula occludens-1 (ZO-1) } & ZO-1_A & AAGCCAGTCACGATCTCCCG & 106 & {$[30]$} \\
\hline & ZO-1_B & GCGCTCTTCCTCTCTGCTCC & & \\
\hline
\end{tabular}

14-16 days. The inoculum was prepared fresh for each dosing day from one aliquot of glycerol-frozen TR2_39, by anaerobic cultivation in four tubes with $45 \mathrm{ml} \mathrm{BSM}$ broth for approximately 48 hours followed by wash in reduced PBS and resuspension in PBS. The optical density was adjusted to $\mathrm{OD}_{600}=10$. Half of the animals were euthanized $\left(\mathrm{CO}_{2}\right.$ chamber and decapitation) on day 14 and the remaining on day 16 after the initial dosing. Animals in the same cage were euthainised sequentially. Weight, water, and feed intake was monitored during the intervention period, as described for the acclimation period. Faecal samples were collected on Day 0 prior to initial dosage, and the day before euthanisation (Day 13 or 15) by collecting defecate directly in tubes. Samples were stored at $-80^{\circ} \mathrm{C}$ until analysis.

\section{In vivo intestinal permeability assay}

On the day of euthanisation, intestinal integrity was determined by measuring the permeability of FITC-dextran, using a similar approach as previously described [9]. Animals were fasted for at least 9 hours before the assay. From each cage, one animal was orally dosed with $0.5 \mathrm{ml}$ $120 \mathrm{mg} / \mathrm{ml}$ FITC-dextran (4 kDa, Sigma-aldrich FD-4) per $100 \mathrm{~g}$ (corresponding to $600 \mathrm{mg} / \mathrm{kg}$ animal) bodyweight while the other was dosed with $0.5 \mathrm{ml}$ PBS per $100 \mathrm{~g}$ bodyweight. Two hours after dosage, animals were euthanized and blood was collected from the neck directly into
$50 \mathrm{ml}$ Falcon tubes with $100 \mu \mathrm{l}$ EDTA $(0.5 \mathrm{M}$, pH 8, Ambion). Blood samples were immediately centrifuged (3800 rpm, $5 \mathrm{~min}$ ) to collect plasma. Plasma was centrifuged again, diluted 1:1 in PBS and stored at $5^{\circ} \mathrm{C}$ until analysis on the same day. Analysis of each sample was done in triplicate by transferring volumes of $60 \mu \mathrm{l}$ plasma-PBS solution to a black 96-well microtiter plate (Proxiplate96 F, Perkin Elmer) and measuring the florescence at excitation $485 \mathrm{~nm} /$ emission $535 \mathrm{~nm}$ (Victor TM X4, Perkin Elmer). Standard curves were prepared for each of the euthanisation days, by adding fixed concentrations of FITC-dextran to plasma-PBS prepared from animals dosed with PBS.

\section{Dissection of animals}

Only animals not dosed with FITC-dextran were dissected to exclude potential effects of FITC-dextran in the downstream analysis. Abdomens were rinsed in $70 \%$ ethanol and dried with a paper towel before the incision. Approximately 2.5-4 cm from the caecum, an ileal section (0.5$1.0 \mathrm{~cm}$ ) was removed and rinsed in PBS before storage in $1 \mathrm{ml}$ RNAlater $^{\circledast}$ (Life Technologies). Colonic sections were taken where the first pellet of content was visible (often 4-5 cm from caecum), and treated the same way as ileal samples. Finally, contents from the caecum were collected, where after the ceacal tissues were washed in PBS and stored in RNAlater. Caecal contents were stored at $-80^{\circ} \mathrm{C}$, 
while tissues in RNAlater ${ }^{\bullet}$ were stored at $5^{\circ} \mathrm{C}$ overnight, and then transferred to $-80^{\circ} \mathrm{C}$.

\section{Collection of caecal content and caecal water}

Caecal contents were weighed and homogenized 1:1 in MilliQ water. Slurries were centrifuged (11.000 g, $15 \mathrm{~min})$ and the pellets stored at $-80^{\circ} \mathrm{C}$ in aliquots of approximately $250 \mathrm{mg}$. Supernatants were centrifuged again and the $\mathrm{pH}$ was determined (Orion Star ${ }^{\mathrm{Tw}} \mathrm{pH}$ Benchtop Meter, Thermo Scientific) before sterile filtration $(0.2 \mu \mathrm{m}$ pore size, Sarstedt) and storage at $-20^{\circ} \mathrm{C}$.

\section{Extraction of bacterial DNA}

DNA was extracted from faecal samples collected before the initial dosing (Day 0), the day before euthanisation (Day 13 or Day 15), as well as from caecal samples using the MoBio PowerLyzer ${ }^{\circ}$ PowerSoil $^{\circ}$ DNA isolation kit (Mobio) following the recommendations of the manufacturer. DNA concentrations were determined using Qubit ds DNA HS assay kit (Invitrogen). DNA was stored at $-20^{\circ} \mathrm{C}$ until further analysis.

\section{Ion Torrent sequencing}

The bacterial composition was determined by sequencing of the V3-region of the 16S rRNA gene in bacterial DNA extracted from caecal contents, and from faecal samples collected before (Day 0) and after the intervention (Day 13 and Day 15) originating from animals not used for the FITC-dextran permeability assay (i.e. total of 24 animals). Amplification of the V3-region and subsequent sequencing was performed using the Ion Torrent PGM platform essentially as previously published [33]. Briefly, the V3-region of the 16S rRNA gene was amplified using a universal forward primer (PBU 5'-Aadapter-TCAG-barcode-CCTACGGGAGGCAGCAG-3') with a unique 10-12 bp barcode for each bacterial community (IonXpress barcode as suggested by the supplier, Life Technologies) and a universal reverse primer (PBR 5'trP1-adapter-ATTACCGCGGCTGCTGG-3'). PCR reactions were conducted with $4 \mu \mathrm{l}$ HF-buffer, $0.4 \mu \mathrm{l}$ dNTP (10 mM of each base), $1 \mu \mathrm{M}$ forward primer, $1 \mu \mathrm{M}$ reverse primer, $5 \mathrm{ng}$ template DNA, and $0.2 \mu \mathrm{l}$ Phusion HighFidelity DNA polymerase (Thermo Scientific) in a reaction volume of $20 \mu \mathrm{l}$. Reactions were run at $98^{\circ} \mathrm{C}$ for 30 seconds followed by 24 cycles of $98^{\circ} \mathrm{C}$ for 15 seconds and $72^{\circ} \mathrm{C}$ for 30 seconds, before $72^{\circ} \mathrm{C}$ for 5 minutes and cooling at $4^{\circ} \mathrm{C}$. Products were separated on a $1.5 \%$ agarose gel with SYBR-safe at $100 \mathrm{~V}$ for 90 minutes, visualized with the Safe Imager ${ }^{\text {Tnx }} 2.0$ (Invitrogen) and bands of expected size (approximately $260 \mathrm{bp}$ ) were excised from the gel. DNA was extracted using MinElute Gel extraction kit (Qiagen) following the recommendations of the manufacturer. DNA concentrations were determined with Qubit HS assay and a library constructed by mixing an equal amount of PCR products from each original community. Sequencing was performed on a 318-chip for Ion Torrent sequencing using the Ion OneTouch ${ }^{\text {tx }} 200$ Template Kit v2 DL. Sequence data were obtained in FASTQ format and further processed using CLC bio genomic workbench (Qiagen) in order to de-multiplex and remove sequencing primers. Further quality trimming using default settings (quality score $=0.05$, trim ambiguous nucleotides $=2$ ) and selection of reads with a final length between $110 \mathrm{bp}-180 \mathrm{bp}$ was performed before exporting reads in FASTA format. The number of good quality reads used for taxonomical assignment ranged from 46,877 to 100,000 . All sequence reads were taxonomically classified using the Ribosomal Database Project Multiclassifier tool [34]. A bootstrap cut-off $\geq 50 \%$, was chosen as recommended for fragments below $250 \mathrm{bp}$ and previously shown to be effective [35]. Relative abundance of bacterial taxa (family level) were determined for each community by comparing the number of reads assigned to a specific family to total number of reads assigned to the bacterial root. To limit variation between animals, the fold-change during the intervention was determined by calculating relative abundance before divided by relative abundance after, and $\log 2$ transformations of these data. Bacterial taxa that were detected either before or after the intervention, but not in the corresponding before/aftersample from the same animal were set to $0.0005 \%$ analogous to 1 read in 200,000 reads.

\section{Quantitative PCR}

The relative abundances of Bifidobacterium spp., Lactobacillus spp., and Akkermansia muciniphila in faecal samples from all animals as well as caecal samples were determined using quantitative PCR in a total reaction volume of $11 \mu \mathrm{l}$ in 384-well microtiter plates using a LightCycler 480 II (Roche Applied Science). Each reaction contained 1X SYBR green mix (Roche Applied Science), $0,2 \mathrm{pmol} / \mu \mathrm{l}$ of each primer (Table 1 ), and $2 \mu \mathrm{l}$ template DNA $(1 \mathrm{ng} / \mu \mathrm{l})$ and setup in four technical replicates with DNA from faecal samples collected before and after the intervention run on the same plate. Reaction conditions were: $95^{\circ} \mathrm{C}$ for $5 \mathrm{~min}, 40$ cycles of $95^{\circ} \mathrm{C}$ for $10 \mathrm{sec}, 60^{\circ} \mathrm{C}$ for $15 \mathrm{sec}$, and $72^{\circ} \mathrm{C}$ for $45 \mathrm{sec}$, followed by melting curve generation $\left(95^{\circ} \mathrm{C}\right.$ for $5 \mathrm{sec}, 65$ for $1 \mathrm{~min}$ and increasing the temperature to $98^{\circ} \mathrm{C}$ with a rate of $0.11^{\circ} \mathrm{C} / \mathrm{sec}$ with continuous fluorescence detection). Data was initially analysed in the LightCycler ${ }^{\circ} 480$ software. Noise band and threshold was set automatically using the LightCycler ${ }^{\circ} 480$ software. Average $\mathrm{C}_{\mathrm{q}}$-values of the four technical replicates calculated by the software were used for data analysis. Single $\mathrm{C}_{\mathrm{q}}$ values differing by more than 2 cycles were considered outliers. The relative abundances of each gene target normalized to the total number of $16 \mathrm{~S}$ rRNA genes (universal bacterial primer) were calculated 
as $\left(1+\mathrm{E}_{\text {universal }}\right)^{\mathrm{Cq} \text { - universal }} /\left(1+\mathrm{E}_{\text {target }}\right)^{\mathrm{Cq} \text { _target }}$ Mean PCR efficiency (E) for each primer set was calculated by use of the LinRegPCR software [36]. If the relative abundance was calculated to be below $0.001 \%$ of the total bacteria (corresponding to the ratio being below $10^{-5}$ ), it was set to half this value.

\section{RNA extraction and cDNA preparation}

Total RNA was extracted from approximately $20 \mathrm{mg}$ of ileum, caecum, and colon tissue using the RNeasy mini kit (Qiagen) following the suppliers recommendations. RNA concentration and purity was determined using Nanodrop Spectrophotometer ND-1000 (Thermo Scientific). Samples with A260/A280 between 1.8 and 2.1 were used in the further analysis. RNA was stored at $-80^{\circ} \mathrm{C}$. The cDNA was prepared immediately from 500 ng RNA in $20 \mu \mathrm{l}$ reactions using the SuperScript VILO cDNA Synthesis Kit (Life technologies) following the suppliers recommendations and stored at $-20^{\circ} \mathrm{C}$ until further use.

\section{Gene expression analysis}

The relative gene expression of the tight junction proteins claudin-1, ZO-1, and occludin, as well as Mucin 2 $(M u c 2)$, involved in mucin production, were determined with quantitative PCR using actin beta $(A c t b)$ and glyceraldehyde 3-phosphate dehydrogenase (Gapdh) as reference genes (Table 1). Reaction conditions were as above and the reactions run under the following conditions; $95^{\circ} \mathrm{C}$ for $5 \mathrm{~min}, 40$ cycles of $95^{\circ} \mathrm{C}$ for $10 \mathrm{sec}, 60^{\circ} \mathrm{C}$ for $10 \mathrm{sec}$, and $72^{\circ} \mathrm{C}$ for $30 \mathrm{sec}$, followed by melting curve preparation $95^{\circ} \mathrm{C}$ for $5 \mathrm{sec}, 65$ for $1 \mathrm{~min}$ and $98^{\circ} \mathrm{C}$ continually. As template, $2 \mu \mathrm{l} 10$-fold diluted cDNA was used. The relative expression was calculated using the geometric mean of the two reference genes.

\section{Trans-epithelial resistance}

The mammalian cell line Caco-2 (passage 15-25) were cultured in DMEM (Gibco) supplemented with 20\% heat inactivated fetal bovine serum (Gibco), 1X Non-essential amino acids (Thermo Scientific), and 1X Pen/strep (Biological industries) at $37^{\circ} \mathrm{C}$ and $5 \% \mathrm{CO}_{2}$. Cells were trypsinized when $60-80 \%$ confluent. A cell suspension of $10^{5}$ cells $/ \mathrm{ml}$ was prepared and $500 \mu \mathrm{l}$ was seeded in the apical compartment of $12 \mathrm{~mm}, 0.4 \mu \mathrm{m}$ pore size Transwell ${ }^{\odot}$ polyester membrane inserts (Corning, USA), while $1.5 \mathrm{ml}$ medium was added to the basolateral compartment. Cells were cultured on the inserts for 21 days with change of medium twice a week. At day 21 the cells were moved to the cellZscope ${ }^{\bullet}$ (nanoAnalytics, Germany). Culture medium was changed, and $760 \mu \mathrm{l}$ and $1.65 \mathrm{ml}$ medium was added to the apical and basolateral compartment, respectively. TER was monitored for 20-23 hours. $76 \mu \mathrm{l}$ medium was then replaced with caecal water, sterile milliQ water (control of the dilution of the cell culture media), or standard cell culture media (cell media control) (control of the cells), resulting in exposure to 5\% caecal water. TER was subsequently measured every hour for 24 hours. All treatments were conducted in three replicates. All caecal water samples obtained from a given animal were analysed on the same day. Caecal water from the animals were used randomly, and placed randomly in the cellZscope ${ }^{\ominus}$. The percentage changes in TER were determined based on the last measured TER before exposing the cells $(t=0)$. In most cases an average of the three replicates was calculated; however for a few samples only two replicates were used.

\section{Statistics}

All data analysis was conducted in GraphPad Prims version 5.0 for Windows (GraphPad Software, CA, USA.) if not otherwise stated. Differences in animal weight, water intake, feed intake, FITC-dextran plasma concentrations, and caecal water $\mathrm{pH}$ between groups were assessed by one-way ANOVA with Bonferroni post-test or KruskalWallis Dunns post-test for non-normally distributed data. The Metastats tool [37] was used for $16 \mathrm{~S}$ rRNA gene sequence analysis using non-parametric t-tests based on 1000 permutations and setting the false discovery rate $q=0.05$ as significant. For selected bacterial groups the relative abundances and fold-changes, determined by both $16 \mathrm{~S}$ rRNA gene sequencing and qPCR, were also compared between CON and both XOS and BIF using MannWhitney $U$-test. Log 2 transformed fold changes were compared to a hypothetical median of zero using the Wilcoxon signed rank test. Differences in gene expression of tight junction proteins and $M u c 2$ between different types of tissue were determined for the CON group by one-way ANOVA with Bonferroni post-test or Kruskal Wallis test with Dunns post-test (not normally distributed data). Differences between CON and XOS or BIF for the individual tissues were determined using Mann-Whitney $U$-test. Correlation analysis was determined using the Spearman correlation, considering $\mathrm{P}<0.05$ to be significant. The $\mathrm{X}^{2}$-test was used to compare the number of observed differences between faecal and caecal samples in the three groups.

\section{Results}

\section{Animal growth, feed, and water intake}

There were no significant differences in animal weight gain between the three groups (Figure 1). Additionally, no significant differences in water and feed intake between the three groups were recorded (data not shown).

\section{Bacterial composition}

Bacterial community analysis at phylum level based on $16 \mathrm{~S}$ rRNA sequencing of faecal samples from 24 animals (one from each cage) before intervention revealed variation in 


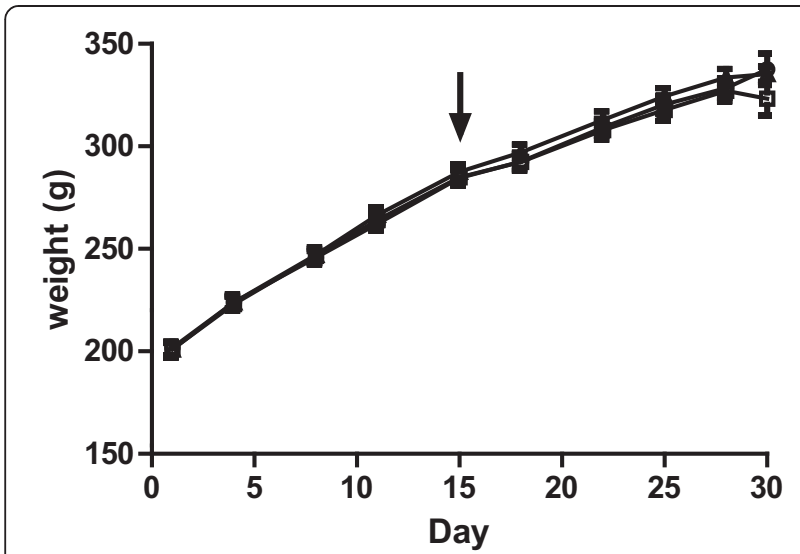

Figure 1 Animal weight gain during the study. Mean with SD is illustrated for each treatment group; CON (circles), XOS (triangles), and BIF (squares). The arrow indicates initiation of the dosing period.

the relative abundance (Figure 2A), and markedly Actinobacteria varied approximately 100 -fold from $0.085 \%$ to $10.9 \%$ and Bifidobacteriaceae 10,000-fold from $0.001 \%$ to $10.7 \%$ between individual animals (Figure 2B). Significant negative correlations were found between Bacteroidetes and Firmicutes $(\mathrm{P}<0.0001, \mathrm{R}=-0.82)$ and Firmicutes and Actinobacteria $(\mathrm{P}=0.019, \mathrm{R}=-0.48)$ and also a negative correlation between Bacteroidetes and Actinobacteria $(\mathrm{P}=$ $0.023, R=0.46)$. No significant differences in relative abundances before and after intervention were found between any of the detected bacterial families in faecal samples from the two intervention groups as compared to the CON group after correction for multiple testing (Figure 3). Neither did principal component analysis of sequencing data at the family-level show any clustering of samples according to intervention group (data not shown). Additionally, no differences in the fold-change (after/before) of any of the detected bacterial families were found between the groups after correction for multiple testing (data not shown). We did however observe differences in the mean relative abundances of several bacterial families between faecal samples and caecal content samples (Table 2).

Analyses of relative abundance and fold-change during the intervention for bacteria belonging to the Bifidobacteriaceae and Lactobacilliaceae were conducted separately as we hypothesized these groups to be affected and also included qPCR-based assessment of the relative abundance of Bifidobacterium spp., Lactobacillus spp., and Akkermansia muciniphila (Figure 4). Taken together, results obtained by qPCR (Figure 4B, D, and F) appeared very similar to the sequencing data (Figure $4 \mathrm{~A}, \mathrm{C}$, and $\mathrm{E}$ ). Fold-change data show that Lactobacillus spp. increased in the CON group $(\mathrm{P}=0.014)$ and the $\mathrm{BIF}$ group $(\mathrm{P}=$ 0.0018 ) compared to baseline (qPCR data). In addition, $A$. muciniphila significantly increased compared to baseline in the XOS intervention group $(\mathrm{P}=0.014)$. There were no significant differences in fold-change for either of the bacterial taxa between the control and the two treatment groups. Sequencing data revealed a trend for a larger foldchange of Bifidobacterium spp. in the XOS group than in the CON group $(\mathrm{P}=0.10)$, however this was not confirmed by qPCR $(P=0.19)$. Nevertheless, qPCR showed that the relative abundance of Bifidobacterium spp. in faeces (Figure 4D) was higher in the XOS group than in the CON group $(P=0.044)$, while this was not confirmed by sequencing data (Figure $4 \mathrm{C}, \mathrm{P}=0.23$ ).

In caecal content (Figure 4E and F) both the XOS and BIF groups had higher relative abundance of Lactobacillus spp. than the CON group (XOS; $\mathrm{P}=0.04$, BIF; $\mathrm{P}=0.03$ ) according to $\mathrm{qPCR}$, while a tendency for this was confirmed by sequencing analysis (XOS; $\mathrm{P}=0.08, \mathrm{BIF} ; \mathrm{P}=$ 0.08). Additionally, XOS tended to increase Bifidobacteriacae in caecum content $(\mathrm{P}=0.10)$ detected by sequencing.

\section{Intestinal permeability}

No differences in FITC-dextran concentration in the plasma were observed between the three groups (Figure 5A). The results from two animals, one from the CON group, and one from the BIF group, were excluded due to technical errors.

The average caecal water $\mathrm{pH}$ was $7.53 \pm 0.15$ (SD), $7.48 \pm 0.23$, and $7.58 \pm 0.20$ for the XOS group, BIF group, and $\mathrm{CON}$ group, respectively with no significant differences between the groups. Caecal water from all three groups on average significantly increased TER as compared to the controls exposed to water or pure cell media (Figure 5B), but no significant differences were found between the three experimental groups after 24 hours of exposure (Figure $5 \mathrm{C}$ ), although the TER was consistently lower in all time points between 12 and 24 hours after exposure to caecal water from either of the treatment groups as compared to $\mathrm{CON}$ (Figure 5B).

\section{Gene expression}

Differences in gene expression between tissue types were determined for the CON group (Figure 6). Expression of Muc2 was higher in the colonic tissue than in ileal $(\mathrm{P}<$ $0.01)$ and caecal tissue $(\mathrm{P}<0.001)$, and also expression of ZO-1 was higher in colon than ileum $(\mathrm{P}<0.001)$. The expression of claudin-1 and occludin did not differ between the intestinal sections. The relative expression of occludin in colon was higher $(\mathrm{P}=0.04)$ in the XOS group than in the CON group (Figure $6 \mathrm{C}$ ). No other significant differences between the groups were found.

Correlations between gene expression of epithelial cells, measures of intestinal integrity and relative abundance of selected bacterial groups

No significant correlations were found between the relative abundance of Bifidobacterium spp., Lactobacillus 

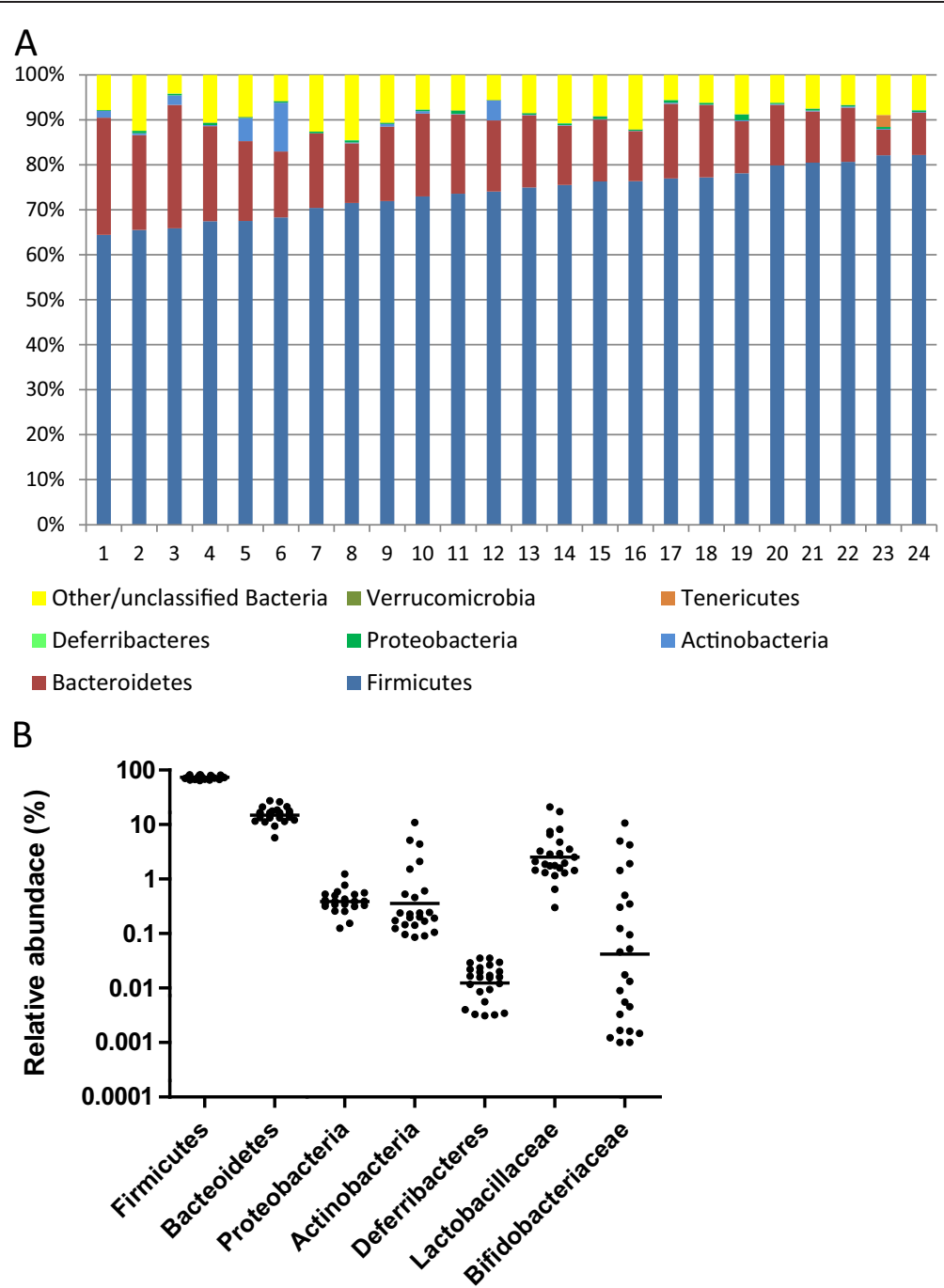

Figure 2 Bacterial community composition of individual animals before intervention based on 16S rRNA gene sequencing. A: Bacterial community composition at phylum level for one animal from each of the 24 separate cages. Columns are ordered with increasing relative abundance of Firmicutes. B: The relative abundance for selected phyla and families are shown as dot-plots with geometric average indicated by a horizontal line.

spp. or Akkermansia muciniphilla in caecal content and faecal samples (qPCR), and relative gene expression of claudin-1, ZO-1, Muc2, and occludin in ileal, caecal and colonic tissue, as well as plasma FITC-dextran concentrations and TER, irrespective of experimental group (data not shown).

\section{Discussion}

Changes in the gut microbial composition have been proposed to affect intestinal integrity [9]. The present study was designed to address this issue further by focusing on the effects of bifidobacterial abundance on microbial community composition and intestinal integrity in male Wistar rats. Two different approaches were used to increase levels of bifidobacteria, namely (i) oral dosage with live cultures of an endogenously isolated strain (probiotic approach) and (ii) oral dosage with XOS, which has previously been shown to stimulate bifidobacterial growth in a mouse model [17] (prebiotic approach).

Experimental animals bred and treated under standardized conditions are generally expected to exhibit less inter-individual variation than a free-living human population and consequently it should require fewer individuals to find effects in dietary intervention studies. Comparison of the animals at base-line (Figure 2A) revealed less variation within the two most abundant phyla, Firmicutes and Bacteroidetes, than reported in human studies [38], but interestingly, for bacteria belonging to the Actinobacteria, a more than 100-fold difference in relative abundance was observed between 


\section{CON \\ XOS \\ BIF}

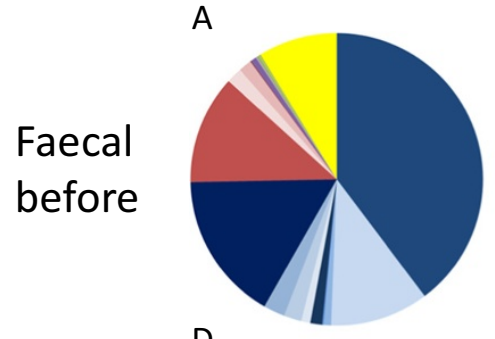

D

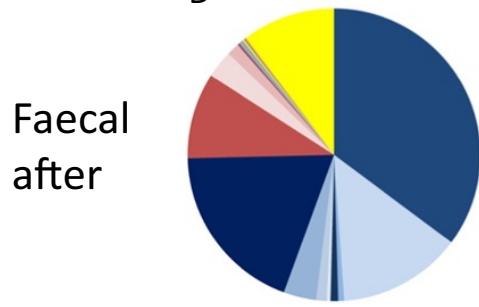

G

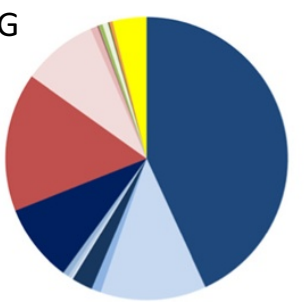

B

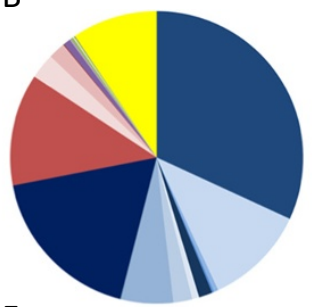

E

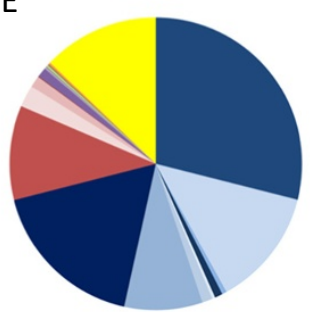

$\mathrm{H}$

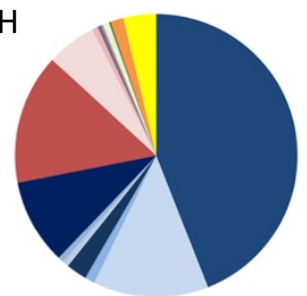

Ruminococcaceae

- Peptostreptococcaceae

Erysipelotrichaceae

- Enterococcaceae

Bacillaceae 2

Rikenellaceae

- Other/unclassified Bacteroidetes

Corynebacteriaceae

n Sutterellaceae

Pasteurellaceae

- Other/unclassified Verrucomicrobia

- Deferribacteraceae
C

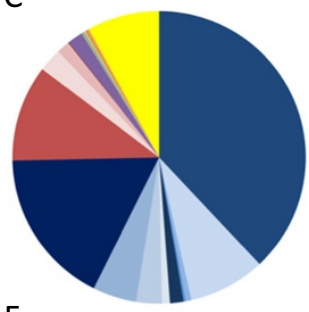

$\mathrm{F}$
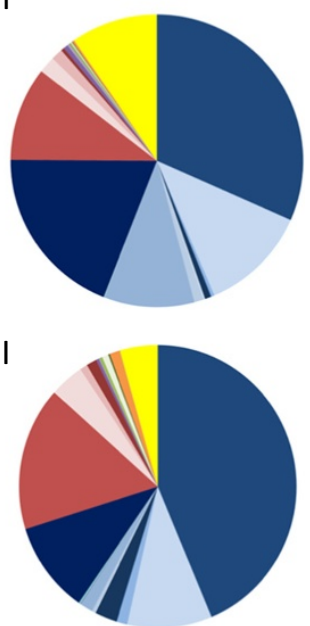

- Peptococcaceae 1
- Clostridiales_Incertae Sedis XI
- Lactobacillaceae
Streptococcaceae
- Other/unclassified Firmicutes
Bacteroidaceae
- Bifidobacteriaceae
- Coriobacteriaceae
Desulfovibrionaceae
-Other/unclassified Proteobacteria
Anaeroplasmataceae
-Other/unclassified Deferribacteres

Figure 3 Bacterial community composition in faecal and caecum content samples based on 16S rRNA gene sequencing. The mean bacterial composition is shown at the family level for faecal samples obtained before intervention (A-C), after intervention (D-F) and caecal content samples (G-I) for animal in CON, XOS and BIF groups. Differences in mean relative abundances were only observed between faecal and caecal samples as detailed in Table 2.

animals. For the Bifidobacteriaceae family, belonging to the Actinobacteria, we observed approximately 10,000fold difference in relative abundance before the intervention commenced (Figure 2B). The high initial level of variation within the Bifidobacteriaceae in this study may impede detection of the expected XOS or BIF driven increase in relative abundance of this bacterial group during the intervention, as such an increase was only detectable by $\mathrm{qPCR}$, and not by sequencing of community-derived $16 \mathrm{~S}$ genes. The increased relative abundance of bifidobacteria following intake of XOS is consistent with a previous study in male Sprague-Dawley rats, which showed increase in both faecal and caecal levels of bifidobacteria following a 14-day intervention with XOS added to feed at 6\% [39] and also an increase is reported in XOS-fed mice [17]. Animals in the BIF group received approximately $2.2-6.2^{*} 10^{8} \mathrm{~B}$. pseudolungum cells every second day during the intervention. This did however not result in higher levels of bifidobacteria in either caecum content or faecal samples at termination. In spite 
Table 2 Differences detected between caecal and faecal samples

\begin{tabular}{|c|c|c|c|c|c|}
\hline & & & CON & xos & BIF \\
\hline Phylum & Family & Sample & Mean \pm SEM & Mean \pm SEM & Mean \pm SEM \\
\hline \multirow[t]{14}{*}{ Firmicutes } & Lachnospiraceae & Faecal & $3.6 \mathrm{E}-01 \pm 3.6 \mathrm{E}-02$ & $2.9 \mathrm{E}-01 \pm 3.7 \mathrm{E}-02$ & $3.2 \mathrm{E}-01 \pm 4.5 \mathrm{E}-02$ \\
\hline & & Caecal & 4.3E-01 $\pm 4.4 \mathrm{E}-02$ & $4.5 \mathrm{E}-01 \pm 3.0 \mathrm{E}-02$ & $4.4 \mathrm{E}-01 \pm 2.8 \mathrm{E}-02$ \\
\hline & Peptostreptococcaceae & Faecal & $7.7 \mathrm{E}-03 \pm 2.2 \mathrm{E}-03$ & $8.2 \mathrm{E}-03 \pm 3.0 \mathrm{E}-03$ & $7.0 \mathrm{E}-03 \pm 2.0 \mathrm{E}-03$ \\
\hline & & Caecal & $2.4 \mathrm{E}-02 \pm 8.7 \mathrm{E}-03$ & $2.4 \mathrm{E}-02 \pm 4.9 \mathrm{E}-03$ & $2.6 \mathrm{E}-02 \pm 5.0 \mathrm{E}-03$ \\
\hline & Erysipelotrichaceae & Faecal & $1.2 \mathrm{E}-02 \pm 3.6 \mathrm{E}-03$ & $1.1 \mathrm{E}-02 \pm 2.9 \mathrm{E}-03$ & $1.1 \mathrm{E}-02 \pm 2.5 \mathrm{E}-03$ \\
\hline & & Caecal & $3.9 \mathrm{E}-03 \pm 8.9 \mathrm{E}-04$ & $6.1 \mathrm{E}-03 \pm 2.7 \mathrm{E}-03$ & $3.8 \mathrm{E}-03 \pm 6.3 \mathrm{E}-04$ \\
\hline & Lactobacillaceae & Faecal & $3.4 \mathrm{E}-02 \pm 8.0 \mathrm{E}-03$ & $8.5 \mathrm{E}-02 \pm 2.7 \mathrm{E}-02$ & $9.7 \mathrm{E}-02 \pm 3.4 \mathrm{E}-02$ \\
\hline & & Caecal & $5.9 \mathrm{E}-03 \pm 3.4 \mathrm{E}-03$ & $6.0 \mathrm{E}-03 \pm 8.0 \mathrm{E}-04$ & $1.5 \mathrm{E}-02 \pm 6.6 \mathrm{E}-03$ \\
\hline & Streptococcaceae & Faecal & $3.6 \mathrm{E}-04 \pm 6.9 \mathrm{E}-05$ & $3.8 \mathrm{E}-04 \pm 1.1 \mathrm{E}-04$ & $2.2 \mathrm{E}-04 \pm 5.2 \mathrm{E}-05$ \\
\hline & & Caecal & $1.3 \mathrm{E}-04 \pm 3.6 \mathrm{E}-05$ & $2.1 \mathrm{E}-04 \pm 8.3 \mathrm{E}-05$ & $1.9 \mathrm{E}-04 \pm 7.1 \mathrm{E}-05$ \\
\hline & Staphylococcaceae & Faecal & $1.2 \mathrm{E}-04 \pm 3.3 \mathrm{E}-05$ & $8.0 \mathrm{E}-05 \pm 1.2 \mathrm{E}-05$ & $1.2 \mathrm{E}-04 \pm 1.4 \mathrm{E}-05$ \\
\hline & & Caecal & $3.6 \mathrm{E}-05 \pm 9.0 \mathrm{E}-06$ & 4.0E-05 $\pm 1.1 \mathrm{E}-05$ & $6.2 \mathrm{E}-05 \pm 2.2 \mathrm{E}-05$ \\
\hline & Veillonellaceae & Faecal & N.D. & N.D. & N.D. \\
\hline & & Caecal & $2.6 \mathrm{E}-04 \pm 1.6 \mathrm{E}-04$ & $9.5 \mathrm{E}-04 \pm 7.5 \mathrm{E}-04$ & $4.8 \mathrm{E}-04 \pm 3.2 \mathrm{E}-04$ \\
\hline \multirow[t]{2}{*}{ Bacteroidetes } & Rikenellaceae & Faecal & $3.0 \mathrm{E}-02 \pm 5.6 \mathrm{E}-03$ & $2.4 \mathrm{E}-02 \pm 5.7 \mathrm{E}-03$ & $1.9 \mathrm{E}-02 \pm 4.6 \mathrm{E}-03$ \\
\hline & & Caecal & $8.6 \mathrm{E}-02 \pm 2.1 \mathrm{E}-02$ & $5.3 \mathrm{E}-02 \pm 1.2 \mathrm{E}-02$ & $4.0 \mathrm{E}-02 \pm 9.4 \mathrm{E}-03$ \\
\hline \multirow[t]{6}{*}{ Actinobacteria } & Micrococcaceae & Faecal & $2.6 \mathrm{E}-04 \pm 5.4 \mathrm{E}-05$ & $1.4 \mathrm{E}-04 \pm 3.1 \mathrm{E}-05$ & $1.7 \mathrm{E}-04 \pm 2.3 \mathrm{E}-05$ \\
\hline & & Caecal & $3.1 \mathrm{E}-05 \pm 1.1 \mathrm{E}-05$ & $2.8 \mathrm{E}-05 \pm 1.0 \mathrm{E}-05$ & $6.5 \mathrm{E}-05 \pm 1.7 \mathrm{E}-05$ \\
\hline & Corynebacteriaceae & Faecal & $6.6 \mathrm{E}-05 \pm 1.5 \mathrm{E}-05$ & $5.9 \mathrm{E}-05 \pm 2.0 \mathrm{E}-05$ & $5.4 \mathrm{E}-05 \pm 1.1 \mathrm{E}-05$ \\
\hline & & Caecal & $1.9 \mathrm{E}-05 \pm 6.3 \mathrm{E}-06$ & $1.0 \mathrm{E}-05 \pm 4.6 \mathrm{E}-06$ & $5.8 \mathrm{E}-05 \pm 3.9 \mathrm{E}-05$ \\
\hline & Coriobacteriaceae & Faecal & $1.5 \mathrm{E}-03 \pm 3.2 \mathrm{E}-04$ & $1.7 \mathrm{E}-03 \pm 1.9 \mathrm{E}-04$ & $1.9 \mathrm{E}-03 \pm 4.6 \mathrm{E}-04$ \\
\hline & & Caecal & $2.4 \mathrm{E}-04 \pm 6.1 \mathrm{E}-05$ & $2.5 \mathrm{E}-04 \pm 4.8 \mathrm{E}-05$ & $5.5 \mathrm{E}-04 \pm 1.4 \mathrm{E}-04$ \\
\hline \multirow[t]{4}{*}{ Proteobacteria } & Desulfovibrionaceae & Faecal & $1.3 \mathrm{E}-03 \pm 4.9 \mathrm{E}-04$ & $9.9 \mathrm{E}-04 \pm 5.6 \mathrm{E}-04$ & $1.1 \mathrm{E}-03 \pm 5.6 \mathrm{E}-04$ \\
\hline & & Caecal & $5.9 \mathrm{E}-03 \pm 1.1 \mathrm{E}-03$ & $5.7 \mathrm{E}-03 \pm 3.1 \mathrm{E}-03$ & $6.5 \mathrm{E}-03 \pm 2.2 \mathrm{E}-03$ \\
\hline & *Hyphomicrobiaceae & Faecal & N.D. & N.D. & $1.9 \mathrm{E}-06 \pm 1.9 \mathrm{E}-06$ \\
\hline & & Caecal & $3.2 \mathrm{E}-05 \pm 9.8 \mathrm{E}-06$ & $4.2 \mathrm{E}-05 \pm 1.9 \mathrm{E}-05$ & $3.9 \mathrm{E}-05 \pm 2.1 \mathrm{E}-05$ \\
\hline \multirow[t]{2}{*}{ Deferribacteres } & Deferribacteraceae & Faecal & $1.0 \mathrm{E}-04 \pm 2.4 \mathrm{E}-05$ & $1.3 \mathrm{E}-04 \pm 6.0 \mathrm{E}-05$ & $1.1 \mathrm{E}-04 \pm 2.0 \mathrm{E}-05$ \\
\hline & & Caecal & $4.1 \mathrm{E}-04 \pm 9.2 \mathrm{E}-05$ & $4.1 \mathrm{E}-04 \pm 1.3 \mathrm{E}-04$ & $3.5 \mathrm{E}-04 \pm 8.3 \mathrm{E}-05$ \\
\hline
\end{tabular}

Mean \pm SEM are shown and highlighted in boldface for those families with significant differences after correction for False Discovery Rate ( $q<0.05$ ). *Note that the family Hyphomicrobiaceae contains the genera Gemmiger, which shows high 16S rRNA gene sequence homology to members of the Ruminococcaceae family (Firmicutes), and may thus be taxonomically misplaced.

of the fact that the bifidobacterial strain applied was isolated from similar rats, we speculate that the strain did not colonize and/or proliferate in the rat gut, resulting in washout before faecal samples were obtained approximately 24 hours after the last dosage. A study addressing intestinal transit of $B$. bifidum following gavage in mice showed a peak in the abundance of this strain in faeces at around 6 hours after dosage and subsequently a significant reduction after 18 hours [40]. Alternatively, the dosing level was too low to have an effect or bifidobacterial cells may not have survived passage through the acidic environment of the rat stomach.

Quantitative PCR as well as 16S rRNA amplicon sequencing revealed higher caecal levels of Lactobacillus spp. in both the XOS and BIF groups compared to the CON groups after intervention (Figure 4E-F). This is consistent with a prebiotic effect of XOS [6] and confirms that increasing the abundance of one bacterial group may influence the abundance of another through e.g. metabolic cross-feeding processes [41] or by changing environmental conditions such as $\mathrm{pH}$. Detection of significant differences in the relative abundance of Lactobacillus spp. between the groups was facilitated by a relatively low initial variation of Lactobacilliaceae (approximately 70-fold) compared to Bifidobacteriaceae (Figure 2B). Quantatative PCR is anticipated to result in better quantification than amplicon sequencing, especially for low-abundant bacterial groups, due to the low 
A

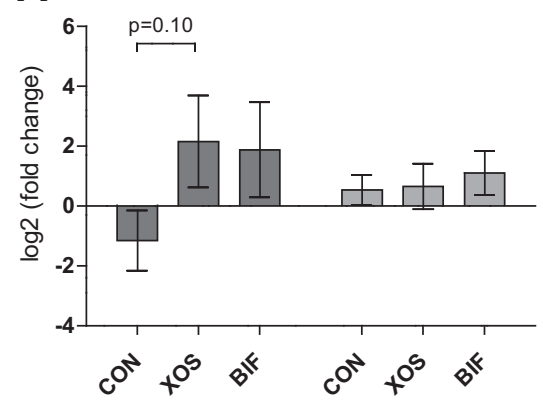

C

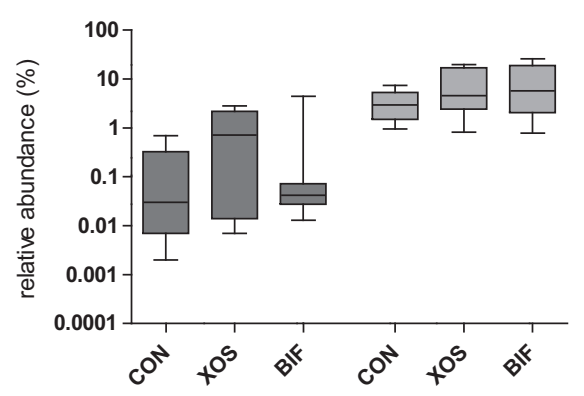

$E$

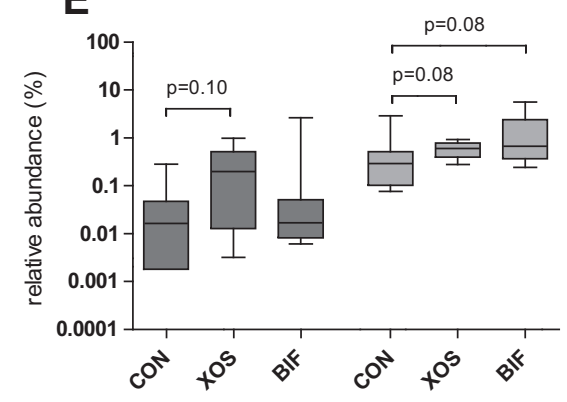

B

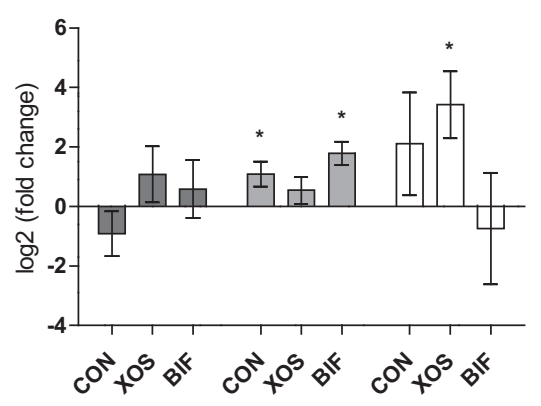

D

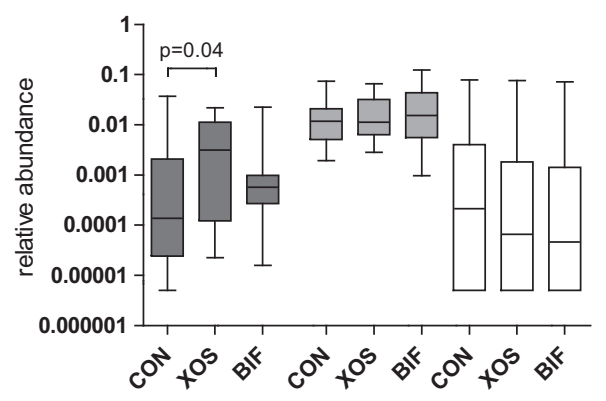

$\mathbf{F}$

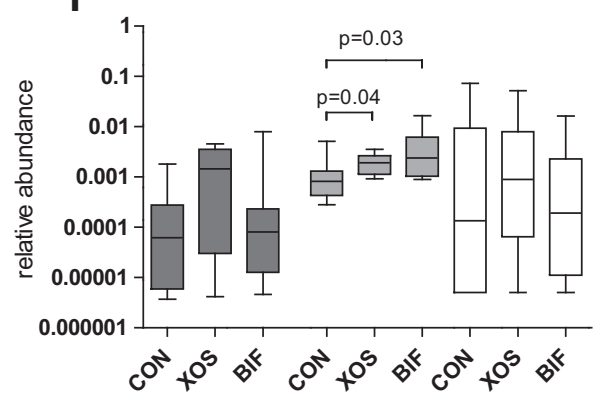

Figure 4 Fold changes and relative abundances determined by $16 \mathrm{~S}$ rRNA gene sequencing and qPCR. Columns show means with SEM (A-B) or box and whisker plots with full range (C-F) for Bifidobacteriaceae (dark grey) and Lactobacillacae (light gray) determined by high through-put sequencing (A,C \& E) and for Bifidobacterium spp. (dark grey), Lactobacillus spp. (light gray) and Akkermansia muciniphilla (white), determined by GPCR (B,D and F). Akkermansia muciniphilla was not included in 165 sequencing due to low abundance. Analysis were performed on community DNA extracted from faecal samples (A-D) or caecum content (E-F). In panels $\mathbf{A}$ and $\mathbf{B}$, significant differences from baseline are indicated with asterisks $(p<0.05)$. Observed differences between groups are indicated with $P$-values.

absolute number of sequence reads in the latter. In the present study we observe only slightly more significant differences by the qPCR approach compared to the sequencing approach (Figure 4) indicating only marginally higher power.

The mucin degrading species A. muciniphila was included in the qPCR analysis, due to its status as potential marker for intestinal health (reviewed by [42]). An increase in levels of $A$. muciniphila after the intervention compared to baseline was found only in the XOS group (Figure 4B). This may be explained by a XOS-induced increased production of mucin, as A. muciniphila is capable of degrading mucin as sole carbon source [43]. Also A. muciniphila is reported to be reduced in patients suffering from disruption of the gut mucus layer due to mucosal inflammation [44] as well as in ob/ob mice [45]. Prebiotics have previously been shown to normalize, hence increase, $A$. muciniphila abundance in obese and type 2 diabetic mice and also administration of viable $A$. muciniphila was connected to improvement of metabolic disorders in mice fed a high-fat diet, potentially due to reestablishment of the mucus layer [45]. Nevertheless, we observed no differences in expression of the mucin gene (Muc2) between the three experimental groups in any of the intestinal segments (Figure 6B). However, as the actual amount of mucus was not determined, this does not exclude the possibility of increased mucin levels in the XOS group due to post-transcriptional alterations and/or 


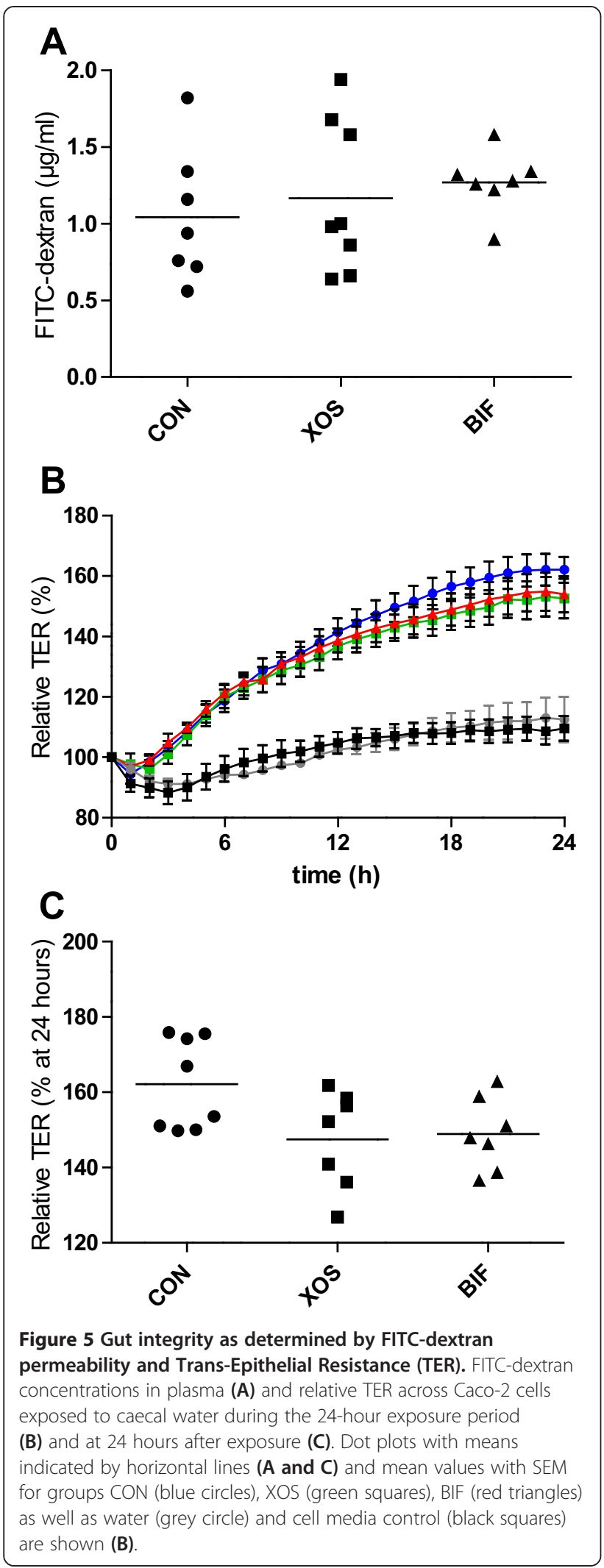

increased expression of other mucin encoding genes. Previously increased levels of mucin secretion were reported in animals fed FOS $[14,18,46]$. Mucins secretion was also increased in humans, but this was not connected to altered permeability for CrEDTA [47].

The overall mean gut microbiota composition in faecal samples was very similar in all three groups before the intervention and remained so during the intervention (Figure 3). No differences in microbiota composition after the interventions were observed between treatment groups after correction for multiple comparisons (Figure 3). We observed several bacterial families which differed in mean relative abundance in caecum content compared to faecal samples, including higher levels of Actinobacteria and lower levels of Peptostreptococcaceae and Veillonellaceae associated with faecal samples in all three intervention groups (Table 2). We observed fewer families that differed in relative abundance between faeces and caecum content in the XOS and BIF groups than in the control group but this was not significant $\left(\mathrm{X}^{2}\right.$-test).

Measures of rat gut integrity were obtained by three independent measures namely (i) permeability of FITCdextran molecules across the epithelial barrier (Figure 5A), (ii) trans-epithelial resistance of Caco-2 cells after exposure to caecal water (Figure 5B-C), and (iii) relative expression of genes encoding tight junctions proteins or mucin (Figure 6). These measures were selected to collectively cover different aspects of gut permeability. Intestinal permeability is mainly determined by paracellular transport between epithelial cells, which has been suggested to be divided into two pathways: The high-capacity "pore pathway" where small molecules (below $4 \AA$ ) can pass, and the low-capacity "leak pathway" where larger molecules may pass (reviewed by [48]). Changes in FITC-dextran permeability indicate a change in the leak-pathway, while changes in TER may indicate changes in both pathways [48]. We found no statistically significant effect on either FITC-dextran permeability or TER after 24 hours between treatment groups and the $\mathrm{CON}$ group of animals (Figure 5A and C). Nevertheless, TER was observed to be consistently higher in the CON than both the XOS and BIF groups from around 12 hours until termination at 24 hours, indicating an increase in permeability in the Caco-2 monolayer during exposure to caecal water from XOS and BIF (Figure 5B). This is consistent with a previously observed trend for a negative correlation between TER and relative abundance of bifidobacteria [11]. Caecal-water collected from CON, XOS of BIF animals increased TER during 24-hours significantly more than water, which was used as control. This suggests that caecal water positively affects tight-junction interaction, which is consistent with similar observations on faecal-water [11]. Expression levels of occludin genes in colonic tissue were significantly higher in the XOS 

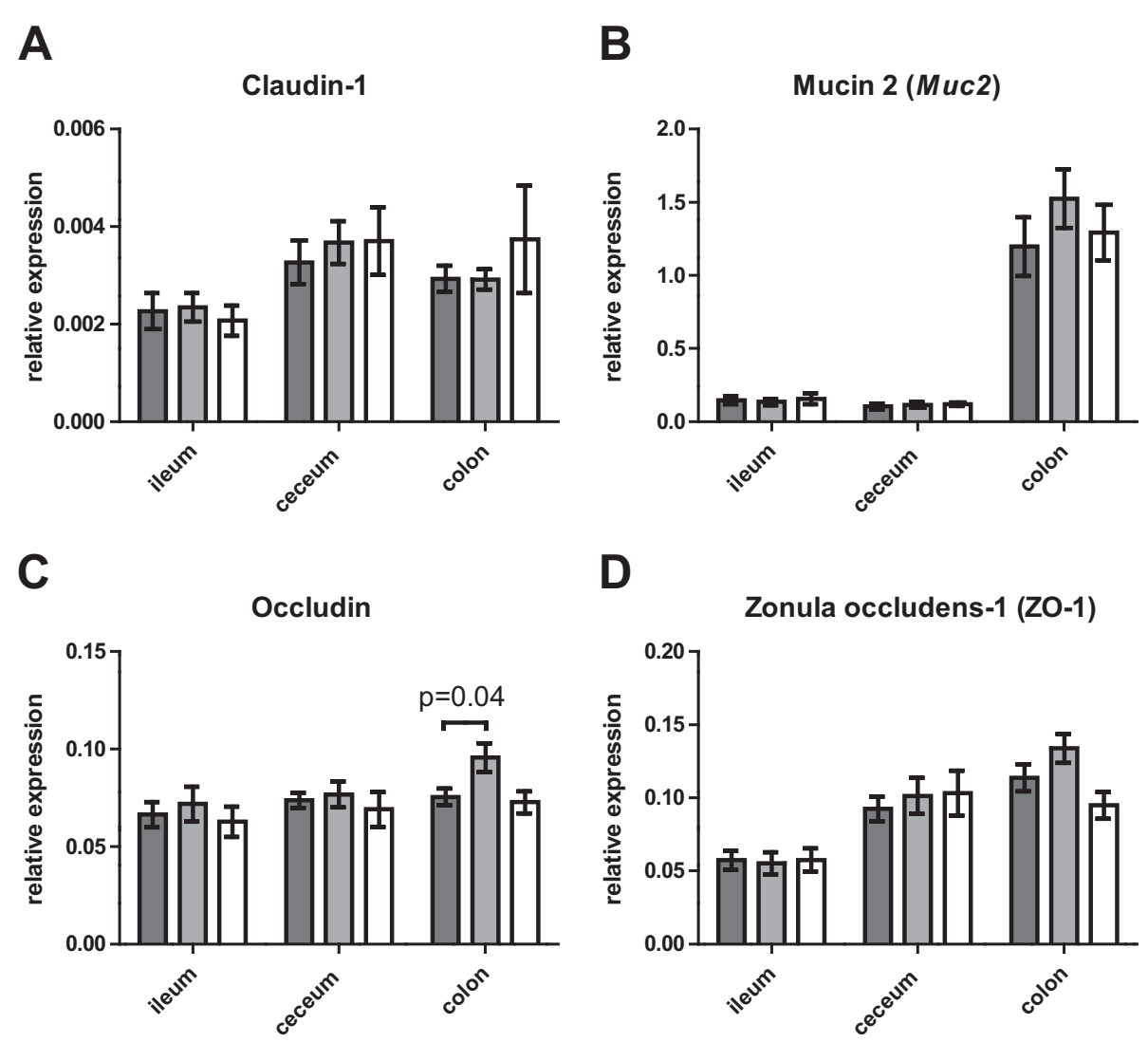

Figure 6 Gene expression of intestinal permeability markers. Mean relative gene expression of claudin-1 (A), Muc2 (B), occludin (C), and ZO-1 (D) in tissue samples obtained from ileum, caecum and colon from animals in CON (dark gray), XOS (light gray) and BIF (white) groups are shown. Observed differences between groups are indicated with p-values. Error bars indicate SEM.

group than in the CON group. Changes in expression of ZO-1 and occludin in ob/ob mice after consumption of prebiotics have previously been studied showing that prebiotic treatment increased levels of Bifidobacterium spp. as well as occludin and ZO-1 expression in jejunum, and also decrease FITC-dextran $(4 \mathrm{kDa})$ permeability [49]. Additionally, high-fat feeding was reported to decrease Bifidobacterium spp., increase intestinal permeability and decrease the expression of ZO-1 and occludin [9]. It should be noted that specific strains of bifidobacteria may have varying effects on markers of intestinal integrity $[19,50,51]$, which could explain the relatively minor effect of the B. pseudolongum isolate in the current study.

\section{Conclusion}

The present study was designed to address the hypothesis that increased levels of bifidobacteria are linked to decreased intestinal integrity caused by modulation of the microbiota, as indicated by previous studies showing increased Salmonella translocation following intake of prebiotics in rodents [14-17]. However, this hypothesis was not confirmed, perhaps because the limited effects of XOS and dosage of bifidobacteria on intestinal bifidobacterial loads were insufficient to induce measurable changes in intestinal integrity. Our observations of increased occludin expression after XOS consumption seem to contradict the hypothesis, while the consistent decrease in TER caused by caecal water from BIF and XOS rats, although not significant, points in a confirmatory direction.

\section{Competing interests}

All authors declare that they have no competing interests.

\section{Authors' contribution}

EGC, MIB and TRL planned the study. EGC performed experimental work, data analysis, and first drafting of the manuscript. TDL coordinated TER analysis. All authors contributed to interpretation of data and final revision of the manuscript. All authors read and approved the final manuscript.

\section{Acknowledgements}

This work was carried out within the Gut, Grain \& Greens (3G) Center, funded by a grant from The Danish Council for Strategic Research (grant no. 11-116163 to T.R.L.). We thank Anne Ørngreen and her department for handling of animals, Rasmus Larsen for help during animal dissection, and Bodil Madsen and Kate Vina Vibefeldt for excellent technical assistance.

\section{Author details}

'Division of Food Microbiology, National Food Institute, Technical University of Denmark, Mørkhøj Bygade 19, Søborg DK-2860, Denmark. ${ }^{2}$ Chr. Hansen A/S, Bøge Allé 10-12, DK-2970 Hørsholm, Denmark. 
Received: 26 February 2014 Accepted: 16 September 2014

Published: 19 September 2014

\section{References}

1. Fukuda S, Ohno H: Gut microbiome and metabolic diseases. Semin Immunopathol 2014, 36:103-114.

2. Vigsnaes LK, Holck J, Meyer AS, Licht TR: In vitro fermentation of sugar beet arabino-oligosaccharides by fecal microbiota obtained from patients with ulcerative colitis to selectively stimulate the growth of Bifidobacterium spp. and Lactobacillus spp. Appl Environ Microbiol 2011, 77:8336-8344

3. Holck J, Lorentzen A, Vigsnaes LK, Licht TR, Mikkelsen JD, Meyer AS: Feruloylated and nonferuloylated arabino-oligosaccharides from sugar beet pectin selectively stimulate the growth of Bifidobacterium spp. in human fecal in vitro fermentations. J Agric Food Chem 2011, 59:6511-6519.

4. Thomassen LV, Vigsnaes LK, Licht TR, Mikkelsen JD, Meyer AS: Maximal release of highly bifidogenic soluble dietary fibers from industrial potato pulp by minimal enzymatic treatment. Appl Microbiol Biotechnol 2011, 90:873-884.

5. Gibson GR: From Probiotics to Prebiotics and a Healthy Digestive System. J Food Sci 2004, 69:141-143.

6. Rastall B: Prebiotics. In Chemical and functional properties of food components. 3rd edition. Edited by Sikorski ZE. Boca Raton, FL, USA: CRC Press; 2007:391-411.

7. Camilleri M, Madsen K, Spiller R, Greenwood-Van MB, Verne GN: Intestinal barrier function in health and gastrointestinal disease. Neurogastroenterol Motil 2012, 24:503-512.

8. John LJ, Fromm M, Schulzke JD: Epithelial barriers in intestinal inflammation. Antioxid Redox Signal 2011, 15:1255-1270.

9. Cani PD, Bibiloni R, Knauf C, Waget A, Neyrinck AM, Delzenne NM, Burcelin R: Changes in gut microbiota control metabolic endotoxemia-induced inflammation in high-fat diet-induced obesity and diabetes in mice. Diabetes 2008, 57:1470-1481.

10. Arrieta MC, Bistritz L, Meddings JB: Alterations in intestinal permeability. Gut 2006, 55:1512-1520

11. Christensen EG, Licht TR, Kristensen M, Bahl Ml: Bifidogenic effect of wholegrain wheat during a 12-week energy-restricted dietary intervention in postmenopausal women. Eur I Clin Nutr 2013, 67:1316-1321.

12. Gill Cl, Heavey P, McConville E, Bradbury I, Fassler C, Mueller S, Cresci A, Dore J, Norin E, Rowland I: Effect of fecal water on an in vitro model of colonic mucosal barrier function. Nutr Cancer 2007, 57:59-65.

13. Aachary AA, Prapulla SG: Xylooligosaccharides (XOS) as an Emerging Prebiotic: Microbial Synthesis, Utilization, Structural Characterization, Bioactive Properties, and Applications. Compr Rev Food Sci F 2011, 10:2-16.

14. Bovee-Oudenhoven IM, Ten Bruggencate SJ, Lettink-Wissink ML, van der Meer R: Dietary fructo-oligosaccharides and lactulose inhibit intestinal colonisation but stimulate translocation of salmonella in rats. Gut 2003, 52:1572-1578

15. Ten Bruggencate SJ, Bovee-Oudenhoven IM, Lettink-Wissink ML, Katan MB, van der Meer R: Dietary fructo-oligosaccharides and inulin decrease resistance of rats to salmonella: protective role of calcium. Gut 2004, 53:530-535.

16. Petersen A, Heegaard PM, Pedersen AL, Andersen JB, Sørensen RB, Frokiaer H, Lahtinen SJ, Ouwehand AC, Poulsen M, Licht TR: Some putative prebiotics increase the severity of Salmonella enterica serovar Typhimurium infection in mice. BMC Microbiol 2009, 9:245.

17. Petersen A, Bergström A, Andersen JB, Hansen M, Lahtinen SJ, Wilcks A, Licht TR: Analysis of the intestinal microbiota of oligosaccharide fed mice exhibiting reduced resistance to Salmonella infection. Benef Microbes 2010, 1:271-281

18. Ten Bruggencate SJ, Bovee-Oudenhoven IM, Lettink-Wissink ML, van der Meer R: Dietary fructooligosaccharides increase intestinal permeability in rats. J Nutr 2005, 135:837-842.

19. Ewaschuk JB, Diaz H, Meddings L, Diederichs B, Dmytrash A, Backer J, Looijer-van LM, Madsen KL: Secreted bioactive factors from Bifidobacterium infantis enhance epithelial cell barrier function. Am J Physiol Gastrointest Liver Physiol 2008, 295:G1025-G1034.

20. Lopez P, Gonzalez-Rodriguez I, Sanchez B, Ruas-Madiedo P, Suarez A, Margolles A, Gueimonde M: Interaction of Bifidobacterium bifidum LMG13195 with HT29 cells influences regulatory-T-cell-associated chemokine receptor expression. Appl Environ Microbiol 2012, 78:2850-2857.
21. Amar J, Chabo C, Waget A, Klopp P, Vachoux C, Bermudez-Humaran LG, Smirnova N, Berge M, Sulpice T, Lahtinen S, Ouwehand A, Langella P, Rautonen N, Sansonetti PJ, Burcelin R: Intestinal mucosal adherence and translocation of commensal bacteria at the early onset of type 2 diabetes: molecular mechanisms and probiotic treatment. EMBO Mol Med 2011, 3:559-572.

22. Bergmann KR, Liu SX, Tian R, Kushnir A, Turner JR, Li HL, Chou PM, Weber CR, De P,l: Bifidobacteria stabilize claudins at tight junctions and prevent intestinal barrier dysfunction in mouse necrotizing enterocolitis. Am J Pathol 2013, 182:1595-1606.

23. Altschul SF, Gish W, Miller W, Myers EW, Lipman DJ: Basic local alignment search tool. J Mol Biol 1990, 215:403-410.

24. Penders J, Vink C, Driessen C, London N, Thijs C, Stobberingh EE: Quantification of Bifidobacterium spp., Escherichia coli and Clostridium difficile in faecal samples of breast-fed and formula-fed infants by real-time PCR. FEMS Microbiol Lett 2005, 243:141-147.

25. Walter J, Hertel C, Tannock GW, Lis CM, Munro K, Hammes WP: Detection of Lactobacillus, Pediococcus, Leuconostoc, and Weissella species in human feces by using group-specific PCR primers and denaturing gradient gel electrophoresis. Appl Environ Microbiol 2001, 67:2578-2585.

26. Heilig HG, Zoetendal EG, Vaughan EE, Marteau P, Akkermans AD, de Vos WM: Molecular diversity of Lactobacillus spp. and other lactic acid bacteria in the human intestine as determined by specific amplification of $16 \mathrm{~S}$ ribosomal DNA. Appl Environ Microbiol 2002, 68:114-123.

27. Collado MC, Derrien M, Isolauri E, de Vos WM, Salminen S: Intestinal integrity and Akkermansia muciniphila, a mucin-degrading member of the intestinal microbiota present in infants, adults, and the elderly. Appl Environ Microbiol 2007, 73:7767-7770.

28. Walter J, Tannock GW, Tilsala-Timisjarvi A, Rodtong S, Loach DM, Munro K, Alatossava T: Detection and identification of gastrointestinal Lactobacillus species by using denaturing gradient gel electrophoresis and species-specific PCR primers. Appl Environ Microbiol 2000, 66:297-303.

29. Zhang YM, Zhou Y, Qiu LB, Ding GR, Pang XF: Altered expression of matrix metalloproteinases and tight junction proteins in rats following PEMF-induced BBB permeability change. Biomed Environ Sci 2012, 25:197-202.

30. Wang HB, Wang PY, Wang X, Wan YL, Liu YC: Butyrate enhances intestinal epithelial barrier function via up-regulation of tight junction protein Claudin-1 transcription. Dig Dis Sci 2012, 57:3126-3135.

31. Shigeshiro M, Tanabe S, Suzuki T: Repeated exposure to water immersion stress reduces the Muc2 gene level in the rat colon via two distinct mechanisms. Brain Behav Immun 2012, 26:1061-1065.

32. Takizawa Y, Kishimoto H, Kitazato T, Tomita M, Hayashi M: Changes in protein and mRNA expression levels of claudin family after mucosal lesion by intestinal ischemia/reperfusion. Int J Pharm 2012, 426:82-89.

33. Milani C, Hevia A, Foroni E, Duranti S, Turroni F, Lugli GA, Sanchez B, Martin R, Gueimonde M, van SD, Margolles A, Ventura M: Assessing the fecal microbiota: an optimized ion torrent $16 \mathrm{~S}$ rRNA gene-based analysis protocol. PLoS One 2013, 8:e68739.

34. Wang Q, Garrity GM, Tiedje JM, Cole JR: Naive Bayesian classifier for rapid assignment of rRNA sequences into the new bacterial taxonomy. Appl Environ Microbiol 2007, 73:5261-5267.

35. Claesson MJ, O'Sullivan O, Wang Q, Nikkila J, Marchesi JR, Smidt H, de Vos WM, Ross RP, O'Toole PW: Comparative analysis of pyrosequencing and a phylogenetic microarray for exploring microbial community structures in the human distal intestine. PLoS One 2009, 4:e6669.

36. Ruijter JM, Ramakers C, Hoogaars WM, Karlen Y, Bakker O, van den Hoff MJ, Moorman AF: Amplification efficiency: linking baseline and bias in the analysis of quantitative PCR data. Nucleic Acids Res 2009, 37:e45.

37. White JR, Nagarajan N, Pop M: Statistical methods for detecting differentially abundant features in clinical metagenomic samples. PLOS Comput Biol 2009, 5:e1000352.

38. Arumugam M, Raes J, Pelletier E, Le PD, Yamada T, Mende DR, Fernandes GR, Tap J, Bruls T, Batto JM, Bertalan M, Borruel N, Casellas F, Fernandez L, Gautier L, Hansen T, Hattori M, Hayashi T, Kleerebezem M, Kurokawa K, Leclerc M, Levenez F, Manichanh C, Nielsen HB, Nielsen T, Pons N, Poulain J, Qin J, Sicheritz-Ponten T, Tims S, et al: Enterotypes of the human gut microbiome. Nature 2011, 473:174-180.

39. Campbell JM, Fahey GC Jr, Wolf BW: Selected indigestible oligosaccharides affect large bowel mass, cecal and fecal short-chain fatty acids, pH and microflora in rats. J Nutr 1997, 127:130-136. 
40. Singh N, Arioli S, Wang A, Villa CR, Jahani R, Song YS, Mora D, Guglielmetti S, Comelli EM: Impact of Bifidobacterium bifidum MIMBb75 on mouse intestinal microorganisms. FEMS Microbiol Ecol 2013, 85:369-375.

41. Flint HJ, Duncan SH, Scott KP, Louis P: Interactions and competition within the microbial community of the human colon: links between diet and health. Environ Microbiol 2007, 9:1101-1111.

42. Ouwerkerk JP, de Vos WM, Belzer C: Glycobiome: bacteria and mucus at the epithelial interface. Best Pract Res Clin Gastroenterol 2013, 27:25-38.

43. Derrien M, Vaughan EE, Plugge CM, de Vos WM: Akkermansia muciniphila gen. nov., sp. nov., a human intestinal mucin-degrading bacterium. Int $J$ Syst Evol Microbiol 2004, 54:1469-1476.

44. Vigsnaes LK, Brynskov J, Steenholdt C, Wilcks A, Licht TR: Gram-negative bacteria account for main differences between faecal microbiota from patients with ulcerative colitis and healthy controls. Benef Microbes 2012. 3:287-297.

45. Everard A, Belzer C, Geurts L, Ouwerkerk JP, Druart C, Bindels LB, Guiot Y, Derrien M, Muccioli GG, Delzenne NM, de Vos WM, Cani PD: Cross-talk between Akkermansia muciniphila and intestinal epithelium controls diet-induced obesity. Proc Natl Acad Sci U S A 2013, 110:9066-9071.

46. Ten Bruggencate SJ, Bovee-Oudenhoven IM, Lettink-Wissink ML, van der Meer R: Dietary fructo-oligosaccharides dose-dependently increase translocation of salmonella in rats. J Nutr 2003, 133:2313-2318.

47. Ten Bruggencate SJ, Bovee-Oudenhoven IM, Lettink-Wissink ML, Katan MB, van der Meer R: Dietary fructooligosaccharides affect intestinal barrier function in healthy men. J Nutr 2006, 136:70-74.

48. Shen L, Weber CR, Raleigh DR, Yu D, Turner JR: Tight junction pore and leak pathways: a dynamic duo. Annu Rev Physiol 2011, 73:283-309.

49. Cani PD, Possemiers S, Van de WT, Guiot Y, Everard A, Rottier O, Geurts L, Naslain D, Neyrinck A, Lambert DM, Muccioli GG, Delzenne NM: Changes in gut microbiota control inflammation in obese mice through a mechanism involving GLP-2-driven improvement of gut permeability. Gut 2009, 58:1091-1103.

50. Fukuda S, Toh H, Hase K, Oshima K, Nakanishi Y, Yoshimura K, Tobe T, Clarke JM, Topping DL, Suzuki T, Taylor TD, Itoh K, Kikuchi J, Morita H, Hattori M, Ohno H: Bifidobacteria can protect from enteropathogenic infection through production of acetate. Nature 2011, 469:543-547.

51. Commane DM, Shortt CT, Silvi S, Cresci A, Hughes RM, Rowland IR: Effects of fermentation products of pro- and prebiotics on trans-epithelial electrical resistance in an in vitro model of the colon. Nutr Cancer 2005, 51:102-109.

doi:10.1186/1756-0500-7-660

Cite this article as: Christensen et al: Dietary Xylo-oligosaccharide stimulates intestinal bifidobacteria and lactobacilli but has limited effect on intestinal integrity in rats. BMC Research Notes 2014 7:660.

\section{Submit your next manuscript to BioMed Central and take full advantage of:}

- Convenient online submission

- Thorough peer review

- No space constraints or color figure charges

- Immediate publication on acceptance

- Inclusion in PubMed, CAS, Scopus and Google Scholar

- Research which is freely available for redistribution 